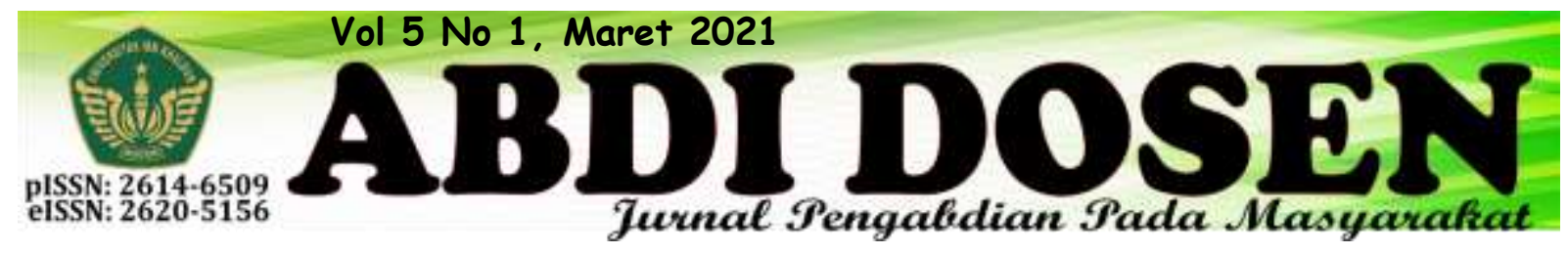

\title{
PENANGGULANGAN KARIES GIGI DENGAN PENAMBALAN DAN PENCABUTAN GIGI SEDERHANA ANAK USIA SEKOLAH
}

\author{
Listrianah $^{1}$, Saluna $\mathrm{D}^{2}$, Msy.Nurhayati ${ }^{3}, \mathrm{Abu} \mathrm{H}^{4}$ \\ listrianah@poltekkespalembang.ac.id ${ }^{1}$ \\ salunadeynilisa@poltekkespalembang.ac.id ${ }^{2}$ \\ msynurhayati@poltekkespalembang.ac.id ${ }^{3}$ \\ abuhamid@poltekkespalembang.ac.id ${ }^{4}$ \\ Program Studi D3 Keperawatan Gigi, Politeknik Kesehatan Kementerian Kesehatan Palembang 1,2,3,4
}

\begin{abstract}
ABSTRAK
Kesehatan gigi anak usia sekolah sangat penting, khususnya usia sekolah dasar. Karena pada usia itu saatnya membangun suatu pundamental pembangunan fisik maupun kecerdasan. Tujuan dari kegiatan pengabdian kepada masyarakat ini adalah untuk meningkatkan derajat kesehatan gigi anak usia sekolah. Oleh sebab itu kesehatan gigi anak usia sekolah harus ditingkatkan melalui pemeliharaan yaitu dengan penambalan gigi dan melakukan pencabutan gigi-gigi yang sudah terindikasi. Metode pelaksanaan penambalan gigi dengan ART (Atraumatic Restorative Treatment) dan pencabutan sederhana dengan Chloraethyl. Peserta yang terlibat dalam kegitan ini adalah seluruh siswa SDN 207 Palembang tahun 2018. Target capaian kegiatan ini adalah meningkatnya derajat kesehatan gigi anak usia sekolah di SDN 207 Palembang tahun 2018. Hasil dari kegiatan ini adalah 51 siswa SDN 207 Kertapati Palembang sudah dilakukan tindakan penambalan dan pencabutan gigi serta penyuluhan tentang pengetahuan kesehatan gigi anak usia sekolah di SDN 207 Palembang. Kesimpulan dari kegiatan ini adalah meningkatkanya derajat kesehatan gigi 51 siswa di SDN 207 Kertapati Palembang tahun 2018. Mereka berpartisipasi dalam pelaksanaan program ini dengan mengikuti kegiatan penambalan gigi, pencabutan gigi dan penyuluhan yang langsung diberikan oleh tim pelaksana setelah dilakukan perawatan kepada murid SDN 207 Palembang. Setelah kegiatan ini selesai murid dapat merasakan manfaat perawatan dengan melalui penambalan, pencabutan gigi dan dapat menjaga kesehatan giginya dengan bekal sedikit pengetahuan yang diberikan oleh tim, sehingga status kesehatan gigi dan mulut menjadi lebih baik dari sebelumnya.
\end{abstract}

Kata Kunci : kesehatan gigi anak usia sekolah, ART, Chloraethyl, penyuluhan pengetahuan kesehatan gigi

\section{Abstract}

Dental health of school age children is very important, especially for primary school age. Because at that age it is time to build a foundation of physical and intellectual development. The purpose of this community service activity is to improve the degree of dental health for school age children. Therefore, the dental health of school-age children must be improved through maintenance, namely by filling the teeth and extracting indicated teeth. The method of implementing dental filling with ART (Atraumatic Restorative Treatment) and simple 
extraction with Chloraethyl. Participants involved in this activity were all of the students of SDN 207 Palembang in 2018. The target of this activity was to improve the degree of dental health of school-age children at SDN 207 Palembang in 2018. The result of this activity was that 51 students of SDN 207 Kertapati Palembang had already taken action. dental fillings and extractions as well as counseling on dental health knowledge of school age children at SDN 207 Palembang. The conclusion of this activity was to improve the dental health of 51 students at SDN 207 Kertapati Palembang in 2018. They participated in the implementation of this program by participating in simple dental filling, tooth extraction and counseling activities that were immediately given by the implementing team after treatment with dental fillings to SDN students 207 Palembang. After this activity, students can experience the benefits of treatment through fillings, tooth extraction and can maintain their teeth health with a little knowledge provided by the team, so that the oral health status is better than before.

Key words: dental health for school-age children, ART, Chlorethyl, dental health education

\section{PENDAHULUAN}

Hasil penelitian yang berjudul "Gambaran Kebersihan Gigi, Sekresi Saliva, dan Kejadian Karies Pada SiswaSiswi SDN 207 Kecamatan Kertapati Kota Palembang (Septia Qurniaty, 2015), menghasilkan bahwa dimana setiap anak memiliki karies 2-3 gigi. Hal ini disebabkan oleh beberapa faktor seperti lingkungan, gigi itu sendiri, saliva, sikap dalam memelihara kesehatan gigi dan mulut. Faktor pendukung lain seperti rendahnya taraf hidup sehingga pemeliharaan kesehatan gigi sering diabaikan, disamping itu juga sulitnya akses pada pelayanan kesehatan juga menjadi faktor penyebab. Oleh sebab itu kami tim pelaksana pengabdian masyarakat Poltekkes Kemenkes Palembang Prodi Diploma Tiga Keperawatan Gigi memberikan peluang agar anak-anak usia sekolah khususnya murid SDN 207 Palembang ini mendapatkan perawatan gigi sesuai dengan kebutuhan mereka.

Kejadian karies pada anak-anak khususnya diusia sekolah akan sangat mempengaruhi tumbuh kembang anak itu sendiri, baik secara fisik maupun intelektualnya. Karena dengan menderita karies gigi (sakit gigi) akan sangat mengganggu belajar, aktifitas, ataupun nafsu makan sehingga pada gilirannya akan menghambat ide-ide dan kretifitas yang dihasilkan oleh anak itu sendiri khususnya murid SDN 207 Kecamatan Kertapati Kota Palembang.

Peran serta orang tua dan pelayanan kesehatan sangatlah penting terhadap penanggulangan kejadian karies pada siswa SDN 207 Kecamatan Kertapati Kota Palembang ini. Faktor nutrisi juga sangat berperan dalam pertumbuhan dan kekuatan gigi, yang lebih penting lagi adalah bagaimana menanamkan kebiasaan memeliharan kesehatan gigi kepada anakanak sehingga gigi dapat bertahan didalam mulut dalam jangka waktu yang lama dalam keadaan sehat.

Karies merupakan suatu penyakit jaringan keras gigi, yaitu email, dentin, dan sementum, yang disebabkan oleh aktifitas jasad renik dalam suatu karbohidrat yang diragikan. Tandanya adalah adanya demineralisasi jaringan keras gigi yang 
kemudian akan diikuti oleh kerusakan bahan organiknya. Akibatnya, terjadi infeksi bakteri dan kematian pulpa serta penyebaran infeksinya ke jaringan periapeks yang dapat menyebabkan nyeri (Kidd, 2012). Karies dapat berkembang lambat atau cepat. Ini tergantung dari banyak faktor seperti diet, komposisi saliva, jumlah bakteri, plak dan mulut dan kebiasaan lainnya (Sriyono, 2012).

Perilaku kesehatan sebagai respons seseorang terhadap stimulus yang berkaitan dengan penyakit (Noto Atmojo , 2002) Lain halnya dengan (Gochman 1998), yang menjelaskan bahwa perilaku atau sifat seseorang seperti harapan, keyakinan, presepsi, dan elemen kgnitif lainnya mempengaruhi perilaku kesehatan.

Berdasarkan hasil survey pendahuluan yang dilakukan sebelum kegiatan pengabdian masyarakat ini dilaksanakan diperoleh gambaran bahwa terdapat banyak kejadian karies dan indikasi pencabutan gigi pada murid SDN 207 Palembang. Melalui pendekatan perawatan kesehatan gigi dengan

\section{METODE}

Permasalahan yang ditemui pada kelompok sasaran dalam hal ini anak usia sekolah yaitu murid SDN 207 Palembang yaitu terdapat kasus karies pada murid rata-rata 2 - 3 gigi, disamping itu juga ditemukan banyak kasus gigi-gigi yang terindikasi pencabutan, dimana masalah ini belum diatasi oleh pihak orang tua maupun oleh murid itu sendiri.

Berdasarkan identifikasi masalah di atas, tim pengabdian kepada masyarakat melakukan langkah pendekatan yang telah disepakati bersama untuk menyelesaikan masalah tersebut, yaitu : dengan metode a). penambalan gigi yang mengalami karies pada murid SDN 207 Palembang dengan penambalan dan pencabutan gigi sederhana dengan melibatkan para guru dalam memberikan dukungan agar kegiatan pengabdian masyarakat ini dapat terlaksana dengan baik dan mencapai sasaran, sehingga diharapkan diperoleh derajat kesehatan gigi anak usia sekolah dalam hal ini murid SDN 207 Palembang akan meningkat.

Oleh karena itu perlu dilakukan perawatan kesehatan gigi melalui tindakan penambalan dan pencabutan gigi sederhana serta penyuluhan pengetahuan kesehatan gigi pada murid SDN 207 Palembang. Cara yang baik untuk mengerjakan ini adalah menempatkan suatu bahan tumpatan yang adhesif ke dalam kavitas, seperti ionomer kaca. Bahan ini akan menempal erat pada gigi dan membentuk seal antara tumpatan dan gigi. Dengan demikian dapat mencegah bakteri apapun masuk kedalam kavitas. Ionomer kaca melepas juga fluoride ke dalam struktur gigi di sekelilingnya dan membuat gigi lebih kuat melawan serangan asam bakteri yang lebih lanjut (Sriyono, 2012)

metode ART (Atraumatic Restorative Treatment) dengan menggunakan bahan tambalan yang bersifat adesif (dapat mengurangi rasa sakit) Metode ini sangat cocok dilakukan dilapangan karena cukup dengan menggunakan peralatan penambalan yang sederhana. Pembersihan karies hanya dilakukan dengan excervasi dengan menggunakan excavator sehingga tidak perlu dilakukan pengeboran, hal ini juga akan mempermudah memotivasi anak-anak agar mau dilakukan penambalan (mengurangi rasa takut anak-anak). b). Dilakukan pencabutan gigi pada gigi-gigi yang sudah terindikasi untuk dilakukan pencabutan. Pencabutan dilakukan secara 
sederhana dengan hanya menggunakan Chloraethyl (obat untuk penghilang rasa sakit ringan pada saat pencabutan) hal ini juga membangun keberanian siswa untuk dilakukan pencabutan giginya. Setelah selesai dilakukan perawatan baik penambalan maupun pencabutan dilakukan penyuluhan pengetahuan kesehatan gigi, sehingga mereka mempunyai bekal untuk menjaga kesehatan giginya.

Kegiatan pengabdian kepada masyarakat ini dilaksanakan di SDN 207 Kecamatan Kertapati Palembang pada tanggal

\section{HASIL DAN PEMBAHASAN}

Kegiatan pengabdian kepada masyarakat ini telah menghasilkan 51 orang murid SDN 207 Kertapati Palembang yang telah dilakukan penambalan, pencabutan gigi serta penyuluhan tentang bagaimana menjaga kesehatan gigi sehari-sehari. Mereka sangat antuasias untuk mendapatakan perawatan giginya. Begitu juga dengan partisipasi mereka dalam pelaksanaan program ini sangat tinggi, sehingga
26 Oktober 2018. Sasaran kegiatan PKM adalah seluruh murid kelas V SDN 207 Palembang yang berjumlah 51 orang. Kegiatan PKM ini dilaksanakan oleh 4 dosen dan dibantu oleh 5 mahasiswa Prodi Diplaoma Tiga Keperawatan Gigi Poltekkes Kemenkes Palembang. Pada kegiatan ini mahasiswa bertugas membantu menyiapkan alat dan bahan yang digunakan untuk melakukan penambalan dan pencabutan gigi serta alat peraga yang digunakan pada saat memberikan penyuluhan.

kegiatan pengabdian kepada masyarakat ini membuahkan hasil yang sangat memuaskan. Setelah kegiatan ini selesai murid dapat merasakan manfaat perawatan dengan penambalan ataupun pencabutan giginya, dan dapat menjaga kesehatan giginya dengan bekal sedikit pengetahuan yang diberikan oleh tim, sehingga status kesehatan gigi dan mulut menjadi lebih baik.

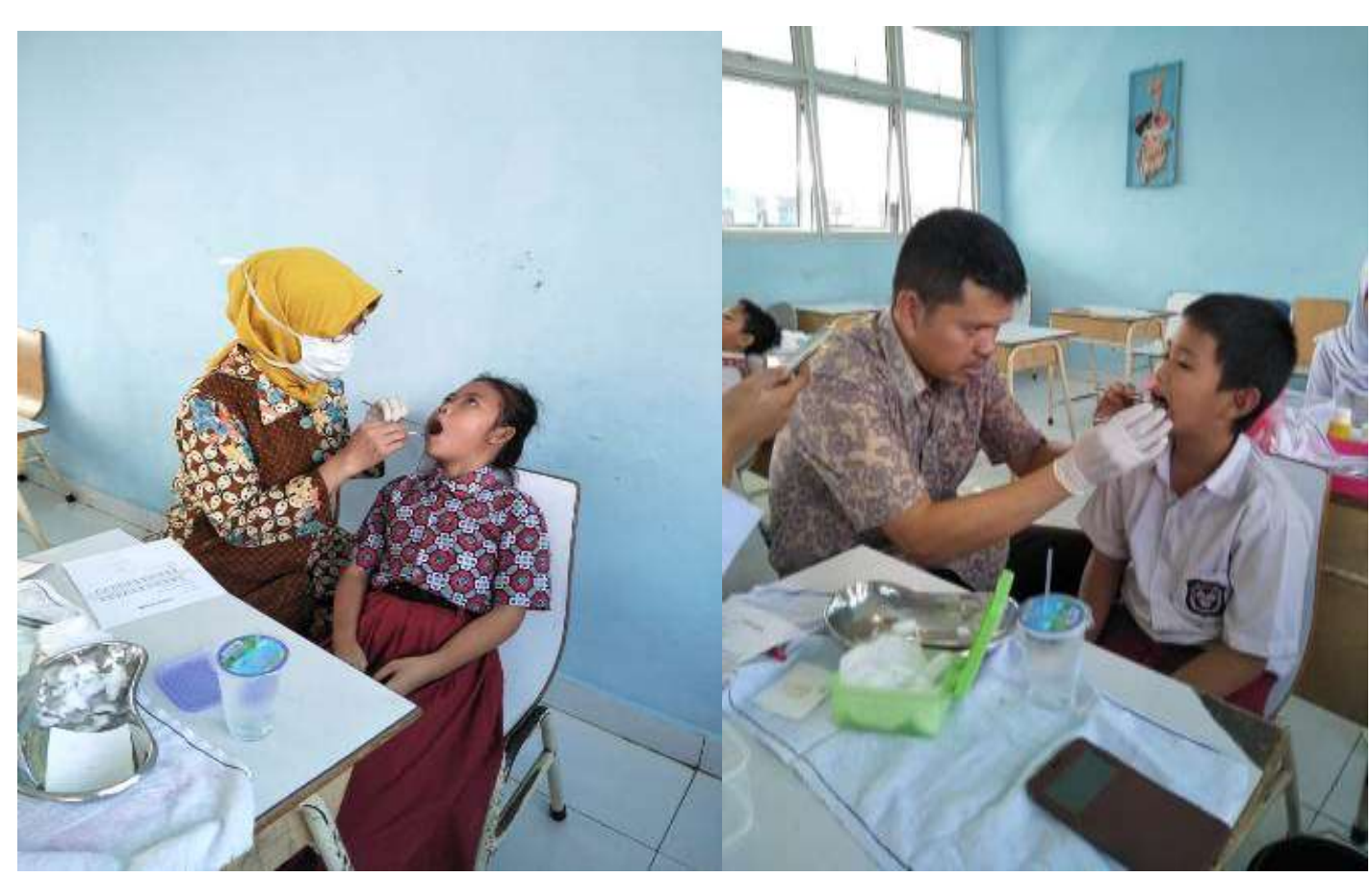

Gambar 1. Pelaksanaan penambalan gigi dengan ART 
Program ini merupakan pengabdian kepada masyarakat yang fokus pada penanaman kebiasaan baik dalam menjaga kesehatan gigi, sehingga dapat meningkatkan derajat kesehatan gigi anak usia sekolah dalam hal ini murid SDN 207 Palembang. Dalam kegiatannya apabila pada seorang muridmempunyai 2 kasus yakni penambalan dan pencabutan, maka pelaksanaan penambalan didahulukan setelah itu baru dilakukan pencabutan. Sehingga satu orang murid dapat diselesaikan dalam satu kali perawatan. Setelah semua murid selesai diberikan perawatan, anak- anak dikumpulkan dalam satu kelas, lalu diberikan penyuluhan tentang bagaimana merawat gigi sehari-hari. Semua kegiatan dilaksanakan di dalam kelas, sehingga memudahkan dalam berkoordinasi, baik kepada orang tua yang sempat menunggu dan guru.

Secara umum, keries dianggap sebagai penyakit kronis pada manusia yang berkembang dalam waktu beberapa bulan atau tahun.Lamanya waktu yang dibutuhkan karies untuk berkembang menjadi suatu kavitas cukup bervariasi, diperkirakan 6-48 bulan (Pintauli, 2010).

Program pelayanan asuhan kesehatan gigi dan mulut dengan melakukan penyuluhan akan meningkatkan status kesehatan gigi anak sekolah dengan menggunakan alat pemeriksaan OHIS (Oral hygiene Index Symplified) memperlihatkan hasil perubahan setelah dilakukan penyuluhan.

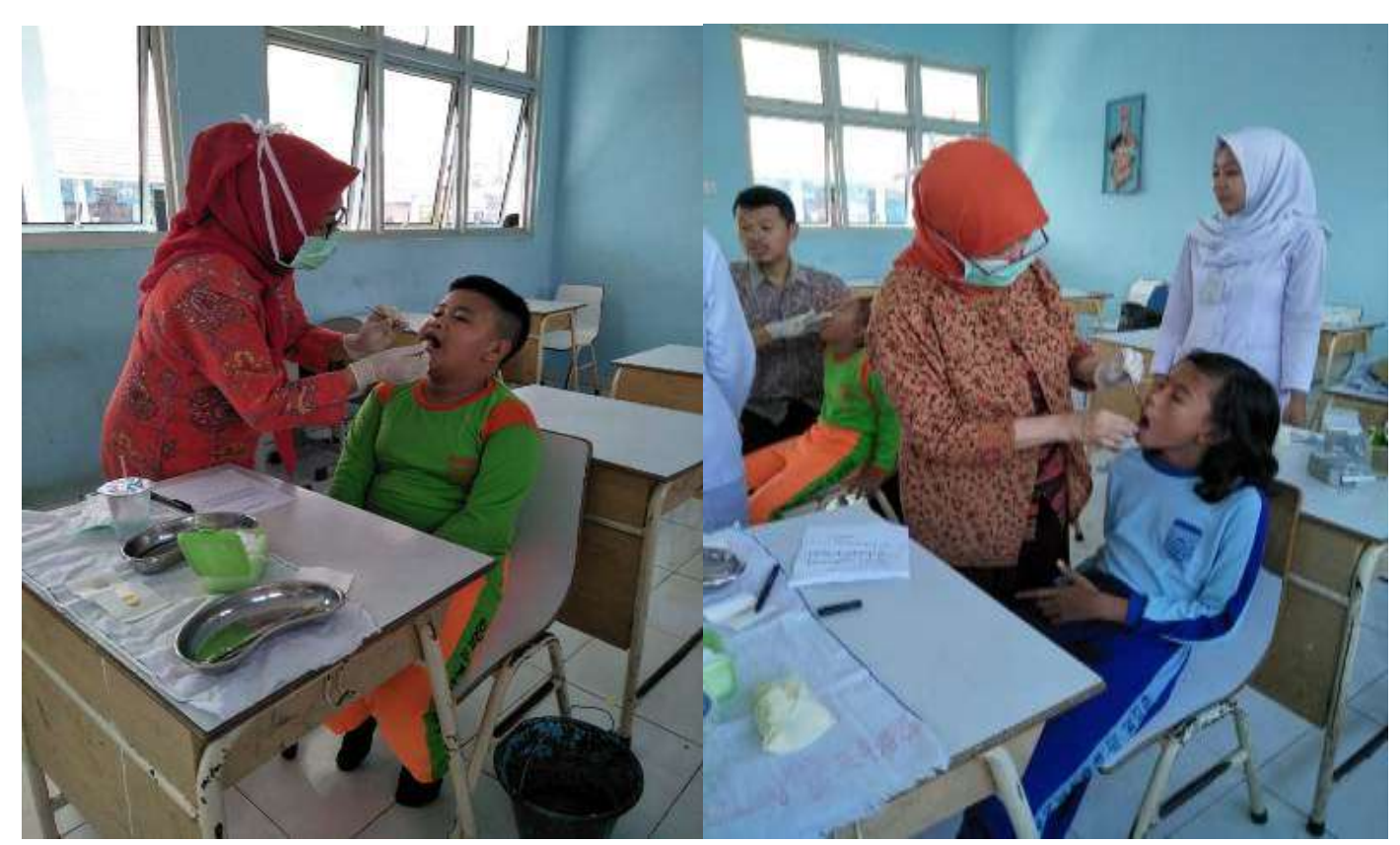

Gambar 2. Pelaksanaan pencambutan gigi dengan Chloraethyl 


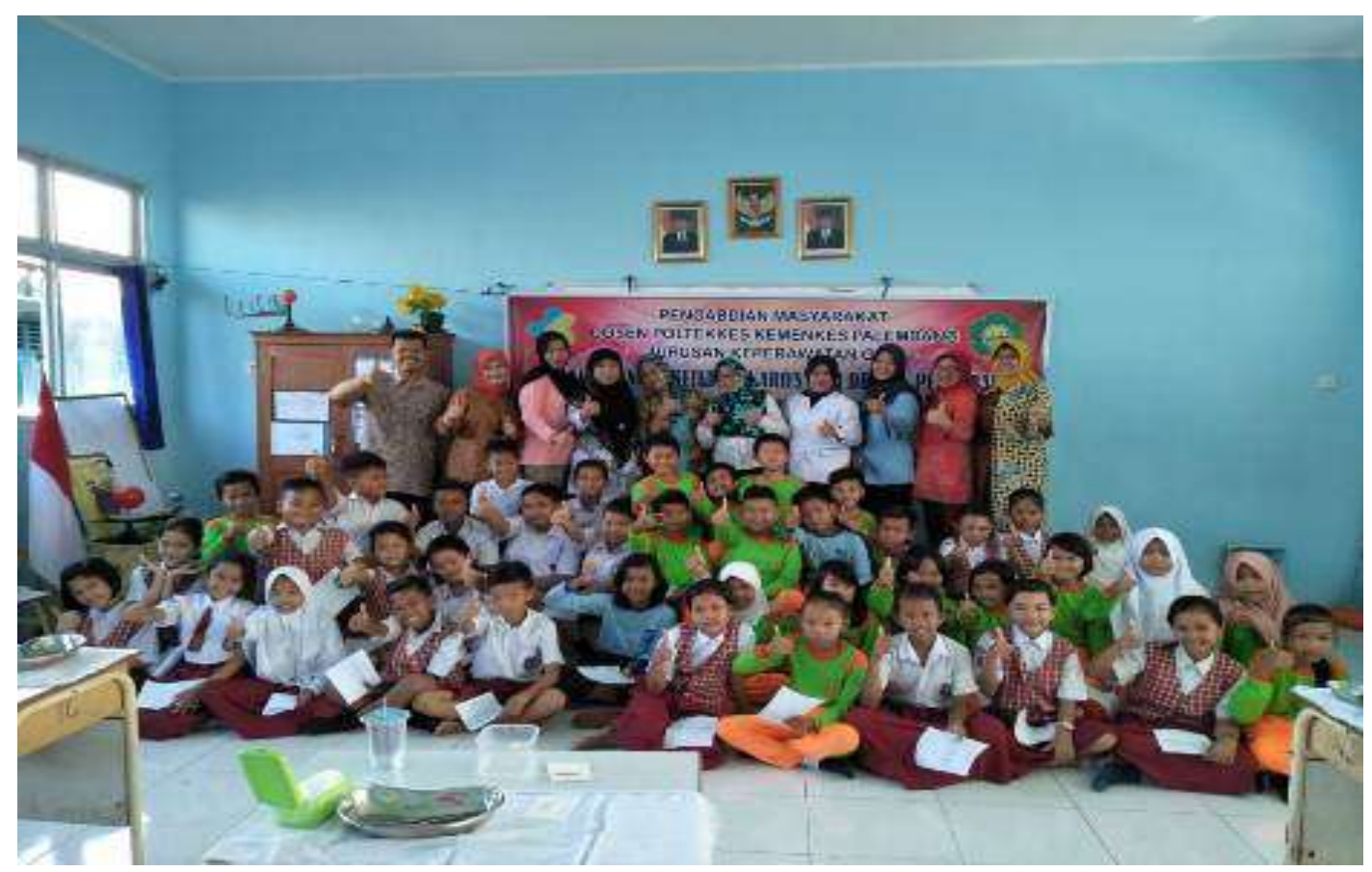

Gambar 3. Penyuluhan kesehatan gigi

Kegiatan pengabdian masyarakat ini dilengkapi dengan melakukan penyuluhan pengetahuan kesehatan gigi yang bertujuan meningkatkan pengetahuan kesehatan gigi dan kecerdasan anak SDN 207 Palembang, sehingga derajat kesehatan giginya dapat meningkat. Kesehatan fisik dan intelektual merupakan faktor penentu dalam mewujudkan tujuan pembangunan Nasional khususnya kesehatan individu, seperti kesehatan gigi dan mulut pada siswa. Hasil survey yang dilakukan Yayasan Kesehatan Gigi Indonesia tahun 2003 terhadap anak-anak di Jakarta menunjukkan bahwa 70\% dari jumlah anak yang menderita karies gigi dan peradangan gusi. Penyakit gigi pada peradangan merupakan ranking ke-10 di Indonesia.

Berdasarkan hasil analisis penelitian Pengaruh Penyuluhan Kesehatan Gigi clan Mulut dengan menggunakan media poster dan media leaflet efektif dalam meningkatkan pengetahuan terhadap kesehatan gigi dan mulut OHIS (Oral
Hygene Index Simplified) serta kecerdasan spiritual pada murid-murid Sekolah Dasar Widuri Lebak Bulus Jakarta Selatan 2012

Memelihara kesehatan gigi anak usia sekolah dilakukan dengan cara memberikan pemahaman tentang kebersihan gigi dan mulut. Oleh karena itu, kepedulian akan kesehatan gigi harus ditanamkan sejak dini, sehingga menghindarkan anak dari masalah penyakit gigi. Seringkali anak lalai untuk menjaga kesehatan gigi yang disebabkan oleh perilaku anak yang negatif. Namun demikian, menanamkan kesadaran anak akan pentingnya kebersihan gigi memang tidak bisa dilakukan secara instan, bahkan butuh kesabaran ekstra. Bila hal ini dilakukan, maka kesadaran menjaga kesehatan gigi ini akan menjadi kebiasaan sampai anak menjadi dewasa. Melalui kegiatan pengabdian masyarakat ini tim telah memberikan penyuluhan tentang bagaimana menjaga kesehatan gigi seharihari. 


\section{KESIMPULAN DAN SARAN}

Adapun kesimpulan dari kegiatan pengabdian kepada msyarakat ini sebagai berikut : 1. 51 murid SDN 207 Palembang telah dilakukan penambalan gigi dengan menggunakan bahan tambalan ART (Atraumatic Restorative Treatment ), 2. 38 murid SDN 207 Palembang telah dilakukan pencabutan gigi sederhana dengan menggunakan Chloraethyl, dan 3. 51 murid SDN 207 Palembang sudah diberikan penyuluhan tentang pengetahuan kesehatan gigi dengan tema Bagaimana memelihara kesehatan gigi sehari-hari. Mereka berpartisipasi dalam pelaksanaan program ini dengan mengikuti kegiatan penambalan gigi, penyuluhan yang langsung diberikan oleh tim pelaksana setelah dilakukan perawatan dengan penambalan gigi kepada murid SDN 207 Palembang. Setelah kegiatan ini selesai kami melakukan suatu evaluasi dengan tanya jawab, hasilnya adalah bahwa murid dapat merasakan manfaat perawatan dengan penambalan dan pencabutan gigi yang sudah terindikasi, dan mendapatkan pemahaman bagaimana menjaga kesehatan

\section{UCAPAN TERIMA KASIH}

Pada kesempatan yang baik ini kami banyak mengucapkan terima kasih kepada Institusi Poltekkes Kemenkes Palembang dalam hal ini Pada kesempatan yang baik ini kami banyak mengucapkan terima kasih kepada Institusi Poltekkes Kemenkes giginya dengan bekal sedikit pengetahuan yang diberikan oleh tim, sehingga status kesehatan gigi dan mulut menjadi lebih baik.

Dengan meningkatnya status kesehatan gigi anak usia sekolah pada SDN 207 Palembang maka akan meningkat pula kesehatan fisik dan intelektual anak, sehingga dapat meningkatkan kecerdasannya. Begitu juga dengan penyakit karies gigi lebih lanjut dapat dicegah melalui kegiatan pengabdian masyarakat ini. Hal ini akan membantu program pemerintah dalam meningkatkan derajat kesehatan anak.

Rekomendasi dari hasil kegiatan pengabdian kepada masyarakat ini adalah: 1). Perlu adanya kerjasama yang baik antara dosen, institusi dan aparat pemerintah sehingga program ini dapat dilaksanakan secara berkelanjutan. 2). Dalam rangka meningkatkan derajat kesehatan anak khususnya kesehatan gigi perlu adanya UKGS (Usaha Kesehatan Gigi Sekolah) yang bekerja sama dengan pelayanan kesehatan setempat.

Palembang dalam hal ini Direktur beserta pejabat yang terkait yang telah memberikan dukungan secara finansial sehingga terselenggaranya kegiatan pengabdian kepada masyarakat ini. 


\section{DAFTAR PUSTAKA}

Barus, A. 2012. Kesehatan gigi dan mulut yang efektif dalam meningkatkan kecerdasan spiritual anak. (Jakarta : Jurnal Poltekkes Kemenkes Jakarta 1)

Kidd,Edwina A.M dan Sally Joyston. 2012. Dasar-Dasar Karies; Penyakit dan Penanggulangan. Jakarta:EGC

Pintauli, Sondang dan Taizo Hamada. 2010. Menuju Gigi dan Mulut Sehat; Pencegahan dan Pemeliharaan. Medan: USU Press

Putri, Megananda Hiranya, dkk. 2010. Ilmu Pencegahan Penyakit Jaringan Keras danJaringan Pendukung Gigi. Jakarta:EGC

Septi Qurniaty, 2015. Gambaran Kebersihan Gigi, Sekresi Saliva dan Kejadian Karies Pada siswa-siswi SDN 234 Kecamatan Kertapati (KTI)
Suwelo, Peranan Pelayanan Kesehatan Gigi Anak

Sriyono, Niken Widyanti. 2012. Pedoman Perawatan Restoratif Autromatik. Jogjakarta: Gajah Mada University Press

Sumber lainnya :

Konservasi Gigi, diakses tanggal 22 Januari 2018, http://ceritapasienrio.com,

Karies gigi pada anak, diakses tanggal 24 Januari 2018 , https://dentosca.wordpress.com,

docdoc,Pencabutan gigi anak, Gambaran Umum, Manfaat dan Hasil yang diharapkan,diakses tanggal 20 Desember 2020, https://www.docdoc.com/id/info/pro cedure/pencabutan-gigi-anak 